\title{
Effect of Ramadan Fasting On Classically Activated, Oxidative Stress and Inflammation of Macrophage
}

\author{
Ardik Lahdimawan ${ }^{1}$, Kusworini Handono ${ }^{2}$, M. Rasjad Indra ${ }^{3}$, \\ Sumarno Reto Prawiro ${ }^{4}$ \\ ${ }^{\text {I} S t u d e n t, ~ P o s t ~ G r a d u a t e, ~ M e d i c a l ~ F a c u l t y ~ o f ~ B r a w i j a y a ~ U n i v e r s i t y, ~ M a l a n g ~ I n d o n e s i a ~ / ~ N e u r o ~ S u r g e r y ~ D e p a r t m e n t, ~}$ \\ Medical Faculty of Lambung Mangkurat University, Banjarmasin Indonesia \\ ${ }^{2}$ Department of Clinical Pathology, Medical Faculty of Brawijaya University, Malang Indonesia. \\ ${ }^{3}$ Department of Phisiology, Medical Faculty of Brawijaya University, Malang Indonesia. \\ ${ }^{4}$ Laboratory of Microbiology, Medical Faculty of Brawijaya University, Malang Indonesia.
}

\begin{abstract}
Ramadan fasting $(R F)$ is stressor that will be altered immune system. Macrophage is one of immune cell and IFNgamma, TNF-alpha, iNOS and SOD is important component on the classically activated, oxidative stress and inflammation of macrophage, so the aim of this study was to determine the effect of RF as stressor on level IFN -gamma, TNF-alpha, iNOS and SOD of macrophage. Twenty seven healthy volunteers male aged 18-22 years (mean $\pm S D 20.26 \pm 1.13$ years) who fasted during Ramadan participated in the study. Blood sampling was conducted on 7 days before Ramadan, days 7 and days 21 of Ramadan. The following were measured by enzyme-linked immunosorbent assay (ELISA) method: IFN-gamma, TNF-alpha, iNOS and SOD of macrophage. Macrophage IFN-gamma on day 21 was increase significant $(p<0.05)$ compared with days 7 . TNF-alpha on days 7 increase significant $(p<0.05)$ compared to before $R F$ and on days 21 was decrease significant $(p<0.05)$ compared with days 7. iNOS on days 7 and 21 increase significant $(p<0.05)$ compared to before RF, and days 21 compared to days 7 . SOD on days 7 and days 21 decrease significant $(p<0.05)$ compared to before RF. The others were not significantly difference. The results obtained indicate that $R F$ altered classically activated macrophage regulation / signaling and increase macrophage function, in which RF induces classically activated, inflammation and reduce oxidative stress of macrophage. This study reveals that macrophage was in eustress condition.
\end{abstract}

Key word: Ramadan fasting, stressor, IFN-gamma, TNF-alpha, iNOS, SOD, classically activated macrophage, oxidative stress, inflammation.

\section{INTRODUCTION}

Ramadan fasting (RF) as a stressor induces stress response in subjects [1]. A psychological and physiological stress, which stimulates the secretion of endorphin are secreted to counter the negative effects of stress [2]. Other study showed that beside endorphin, stresses in humans are associated with impaired endocannabinoid activity [3]. Endogenous cannabinoids play an important role in the physiology and behavioral expression of stress responses. Activation of the hypothalamic-pituitary-adrenal (HPA) axis, including the release of glucocorticoids, is the fundamental hormonal response to stress. Endocannabinoid signaling serves to maintain HPA-axis homeostasis [4]. Profuse study reveals that RF induces stress response on macrophage in which macrophage endorphin increase and macrophage endo-cannabinoids decrease significantly in the end of RF [1].

Beta-endorphin modulated tumor necrosis factor-alpha (TNF-alpha) and interferon-gamma (IFN-gamma) release from lipid-laden macrophages [5]. Beta endorphin significantly and dose dependently enhanced IFN-gamma and IL-2 in human PBMC [6]. Endomorphin-1 inhibited macrophage chemotaxis and the production of superoxide anion by macrophages. On the contrary, endomorphin-1 inhibited TNF-alpha production by macrophages [7]. Induction of TNF-alpha was suppressed by beta endorphin on epidermal Langerhans cells [8]. Other study had shown that there is significant biochemical evidence to suggest that biosynthesis, uptake and degradation of endocannabinoids occur in macrophages and leukocytes [9,10,11].

Reduced macrophage chemotaxis by cannabinoids was observed in a murine model of atherosclerosis, suggesting their strong effect on macrophage migration which is mediated by cannabinoids-2 (CB2) receptor signaling [12], in which IFN-gamma is a mediator of CB2 signaling [13]. IFN-gamma is a potent activator of the bactericidal and cytocidal potential of macrophages [14], and endoccannabinoids-induced reactive oxygen species (ROS) production by macrophages was cannabinoids-1 (CB1)-dependent [15].

Other study reveals that TNF-alpha and IFN-gamma cooperate in the activation of macrophages [16]. Activated macrophages do however possess a markedly enhanced ability to kill and degrade intracellular microorganisms, and for several years, this was the functional criterion used to define an activated macrophage. This 
killing is accomplished by an increase in the production of toxic oxygen species / ROS and an induction of the inducible nitric oxide synthase (iNOS) gene to produce nitric oxide (NO) [17].

We examined the effect of fasting during the lunar month of Ramadan as stressor on IFN-gamma, TNFalpha, iNOS / NO, Superoxide dismutase SOD / ROS of macrophage in a group of 27 healthy males. The main emphasis of this study was to elucidate classically activated, oxidative stress and inflammation of macrophage during RF, as little is known about this topic.

There appears to be at least three different populations of activated macrophages with three distinct biological functions. The first and most well described is the classically activated macrophage whose role is as an effectors cell in T helper 1 (Th1) cellular immune responses. The second type of cell, the alternatively activated macrophage, appears to be involved in immunosuppression and tissue repair. The most recent addition to this list is the type 2-activated macrophage, which is anti-inflammatory and preferentially induces Th2-type humoral-immune responses to antigen [17].

Modulation of macrophage survival is a critical factor in the resolution of inflammatory responses [18]. IFN-gamma is involved in the regulation of nearly all phases of the immune and inflammatory responses, including the activation and differentiation of T cells, B cells, NK cells, macrophages, and others [19]. TNF-alpha has been proposed as a central player in inflammatory cell activation and recruitment and is suggested to play a critical role in the development of many chronic inflammatory diseases [20]. The secretion of TNF-alpha was assessed since macrophages are known to secrete TNF-alpha as a result of cellular oxidative stress [21]. Oxidative stress can have both direct and indirect effects on macrophage function [22].

\section{MATERIAL AND METHODS}

Blood samples were drawn for examination of IFN-gamma, TNF-alpha, iNOS and SOD level from all participant and samples were drawn between 9 am and 12 noon to avoid diurnal variation at 7 days before, days 7 and days 21 of RF.Five milliliters of venous blood from the antecubital vein were collected in an ethylenediaminetetraacetic acid (EDTA) vial. Human monocytes were isolated from buffy coats and cultured for 6 days in 24- or 6-well tissue culture plates (Corning, Corning, NY) as previously described [1,23], with a minor modification: cells were cultured in RPMI 1640 with Penstrep $1 \%$ (Sigma Aldrich), serum free Nabic $0.2 \%$ (Bio World) and FBS $10 \%$ (Gibco Inc), pH 7,2 incubate $37^{\circ} \mathrm{C}, 5 \% \mathrm{CO} 2$. Culture medium and nonadherent cells were removed by aspiration every 3 days of culture, and monolayers were subsequently incubated with fresh culture medium supplemented with $10 \%$ autologous serum $[1,24]$.

Purified macrophage was each resuspended in incubation buffer (sterile pyrogen-free Hanks balanced salt solution [HBSS; Bio-Whittaker], vortexed and centrifuged $1400 \mathrm{rpm} 7$ minute $4^{\circ} \mathrm{C}$. Pellets add with RIPA+PIC+PMSF. Vortexed and incubation on ice for 30 minute. Centrifuge $12.000 \mathrm{rpm}$ for 20 minute at $4^{\circ} \mathrm{C}$. Supernatant kept on $-20^{\circ} \mathrm{C}$ until analyze [1]. IFN-gamma, TNF-alpha, iNOS, SOD level was estimated (twice/duplo) by enzyme linked immunosorbent assay using a commercial ELISA kit (R\&D systems).

Statistical Analysis: One-Sample Kolmogorov-Smirnov Test, mean, ANOVA, Duncan test and Kruskal-Wallis Test were performed using SPSS version 11.5 for Windows.

\section{RESULTS}

The study population consisted of healthy males, medical student in medical school at Brawijaya University. Due to various limitations, including the needs for laboratory examinations, fresh blood to be examined immediately, and adequate blood volumes, most blood samples were unsuitable, leaving only 27 cases eligible for IFN-gamma, TNF-alpha, iNOS and SOD. The subjects were aged 18-22 years (mean \pm SD 20.26 \pm 1.13 years).

Our result reveal that IFN-gamma on days 21 was increase significant $(\mathrm{p}<0.05)$ compared with days 7. TNF-alpha on days 7 increase significant $(\mathrm{p}<0.05)$ compared to before Ramadan and on days 21 was decrease significant $(\mathrm{p}<0.05)$ compared with days 7. iNOS on days 7 and 21 increase significant $(\mathrm{p}<0.05)$ compared to before Ramadan, and days 21 compared to days 7. SOD on days 7 decrease significant ( $<<0.05$ ), but not on days 21 compared to before Ramadan (Table-1). 


\begin{tabular}{|c|c|c|c|c|}
\hline Sampel & $\mathbf{N}$ & Mean \pm SD & ANOVA & Duncan test \\
\hline $\begin{array}{l}\text { IFN } \\
\text { Before Ramadan } \\
\text { Days } 7 \\
\text { Days } 21 \\
\end{array}$ & $\begin{array}{l}27 \\
27 \\
27\end{array}$ & $\begin{array}{l}94.541 \pm 44.9452 \\
83.352 \pm 33.8075 \\
107.348 \pm 38.6487\end{array}$ & $p=0.088$ & $\begin{array}{ll}\text { 1. } & \mathbf{p}>0.05 \\
\text { 2. } & \mathbf{p}>0.05 \\
\text { 3. } & \mathbf{p}<0.05^{*}\end{array}$ \\
\hline $\begin{array}{l}\text { TNF-alpha } \\
\text { Before Ramadan } \\
\text { Days } 7 \\
\text { Days } 21 \\
\end{array}$ & $\begin{array}{l}27 \\
27 \\
27\end{array}$ & $\begin{array}{l}15.456 \pm 7.1458 \\
24.633 \pm 11.5716 \\
19.607 \pm 6.0916\end{array}$ & $p=0.001$ & $\begin{array}{ll}\text { 1. } & \mathbf{p}<0.05 * \\
\text { 2. } & \mathbf{p}>0.05 \\
\text { 3. } & \mathbf{p}<0.05^{*}\end{array}$ \\
\hline $\begin{array}{l}\text { iNOS } \\
\text { Before Ramadan } \\
\text { Days } 7 \\
\text { Days } 21 \\
\end{array}$ & $\begin{array}{l}27 \\
27 \\
27\end{array}$ & $\begin{array}{l}5.0593 \pm 4.81354 \\
16.0815 \pm 11.79958 \\
39.9630 \pm 10.89499\end{array}$ & $\begin{array}{l}\text { chi-square } \\
\mathbf{p}=\mathbf{0 . 0 0 0}\end{array}$ & $\begin{array}{l}\text { Kruskal-Wallis Test } \\
\text { p }<0.05^{*}\end{array}$ \\
\hline $\begin{array}{l}\text { SOD } \\
\text { Before Ramadan } \\
\text { Days } 7 \\
\text { Days } 21 \\
\end{array}$ & $\begin{array}{l}27 \\
27 \\
27\end{array}$ & $\begin{array}{l}68.3396 \pm 14.02350 \\
59.7307 \pm 11.79872 \\
62.0852 \pm 12.27447 \\
\end{array}$ & $p=0.042$ & $\begin{array}{ll}\text { 1. } & \mathbf{p}<0.05^{*} \\
\text { 2. } & \mathbf{p}>\mathbf{0 . 0 5} \\
\text { 3. } & \mathbf{p}>\mathbf{0 . 0 5} \\
\end{array}$ \\
\hline
\end{tabular}

Table-1. Mean, ANOVA and Duncan / Kruskal-Wallis Test of IFN-gamma, TNF-alpha, iNOS and SOD of macrophage before RF, days 7 and days 21. Duncan test 1) before Ramadan compare with days 7, 2) Before Ramadan compare with days 21,3$)$ days 7 compare with days 21. (* = Significant).

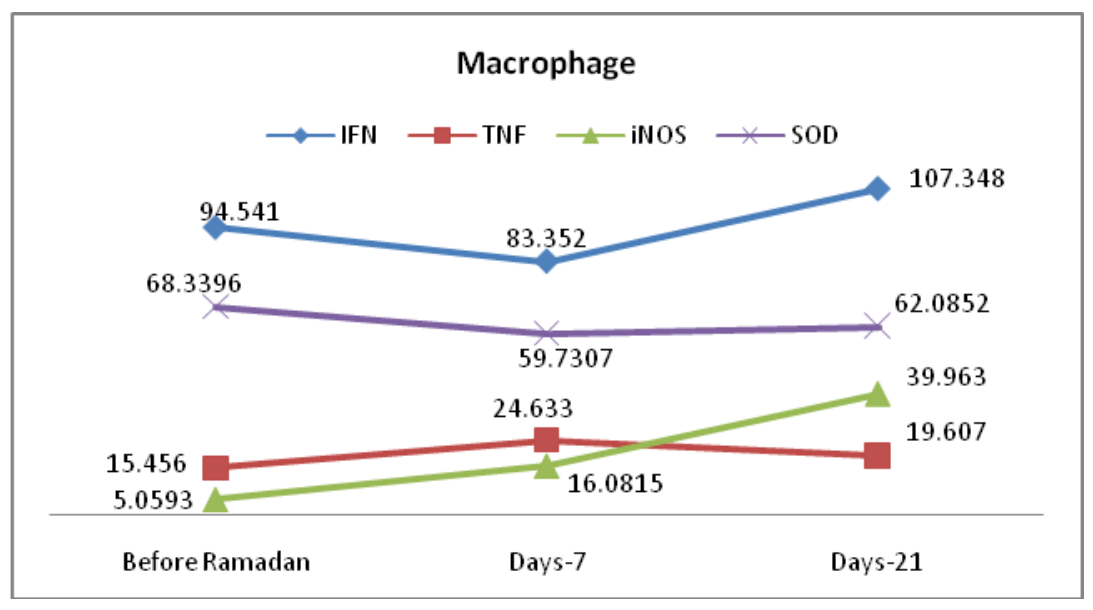

Figure-1. Level IFN-gamma, TNF-alpha, iNOS, SOD of macrophage before RF, days 7 and days 21.

\section{DISCUSSION}

In the old days, activated macrophages were simply defined as cells that secreted inflammatory mediators and killed intracellular pathogens. Things are becoming progressively more complicated in the world of leukocyte biology. Activated macrophages may be a more heterogeneous group of cells than originally appreciated, with different physiologies and performing distinct immunological functions [17].

Macrophages are involved in both innate and adaptive immune responses. Depending on the types of cytokines that macrophages are exposed to, these cells are subjected to classical (Th1), alternative (Th2) activation and Type-2 activation. It is important to remember that macrophages become classically activated by exposure to two signals. The first is the obligatory cytokine IFN-gamma, which primes macrophages for activation but does not in itself activate macrophages. The second signal is TNF-alpha itself or an inducer of TNF $[17,25]$. The key macrophage-activating cytokines in Mycobacterium Tuberculosis (M.tb) infection are TNF-alpha and IFN-gamma [26].

Our study reveals that IFN-gamma of macrophage on days 7 decrease and on days 21 increase not significantly ( $p>$ 0.05) compare with before RF. But days 21 significantly increase compare with days 7 . TNF-alpha of macrophage on days 7 increase significant $(\mathrm{p}<0.05)$ and on days 21 increase not significantly $(\mathrm{p}>0.05)$ compare with before RF. But days 21 significantly decrease compare with days 7 (figure-1). This study shown that RF induce IFN-gamma in the end of RF, although not significantly difference and induce TNF-alpha in early of RF with significantly difference, so these result suggest that RF induce classically activated macrophage in healthy subject. Other study shown that Human macrophages derived from monocytes in vitro through stimulation with a combination of Interleukin (IL)-12 and IL-18 or with macrophage colony-stimulating factor (M-CSF) were able to produce IFN-gamma when further stimulated with a combination of IL-12 and IL-18 [27].

Interferons are cytokines that play a complex and central role in the resistance of mammalian hosts to pathogens. Type I interferon (IFN-alpha and IFN-beta) is secreted by virus-infected cells [28]. Immune, type II, or 
IFN-gamma is secreted by thymus-derived ( $\mathrm{T}$ ) cells under certain conditions of activation and by natural killer (NK) cells $[19,28]$ and can promote macrophage activation (bactericidal activity of phagocytes), mediate antiviral and antibacterial immunity, enhance antigen presentation, orchestrate activation of the innate immune system, coordinate lymphocyte-endothelium interaction, regulate Th1/Th2 balance, and control cellular proliferation and apoptosis $[19,28]$. The IFN-gamma response is itself regulated by interaction with responses to other cytokines including IFNalpha/beta, TNF-alpha, and IL-4 [28].

Interferon-gamma rapidly primes the macrophage via Janus kinase (JAK)1/2- signal transducer and activator of transcription (STAT)1 pathway so that it can subsequently undergo a slower classical type 1 activation upon exposure to Th1 cytokines such as IFN-gamma or other activators, including TNF and lipopolysaccharide (LPS), e.g. in intracellular killing of phagocytosed M.tb [29]. Other study reveals that JAK2, MAP kinase (MEK)1/2, extracellular signal-regulated kinases 1 and 2 (Erk1/Erk2) and STAT1alpha are key players in the IFNgamma-inducible generation of NO by macrophage [30].

Macrophages that have been primed with IFN-gamma alone should not make NO, provided the system is free of LPS (a common contaminant in recombinant IFN-gamma). In the human system, the activation of macrophages is somewhat more difficult to definitively determine, as monocyte-derived macrophages from peripheral blood generally do not produce NO in response to the classical activating stimuli [17]. Exogenous addition of TNF-alpha, however, activates macrophages only after priming with IFN-gamma [31].

Exogenous TNF can act as the second signal, but the physiologically relevant second signal is generally the result of Toll-like receptor (TLR) ligation, which induces endogenous TNF production by the macrophage itself $[17,31]$. Thus, classically activated macrophages are developed in response to IFN-gamma, along with exposure to a microbe or microbial product such as LPS. In the murine system, these cells are now easily identified by virtue of their production of NO $[17,32,33]$. TNF-alpha is a pleiotropic cytokine produced predominantly by macrophages and interestingly are also highly responsive to TNF-alpha [31,34].

Tumor Necrosis Factor super family is a group of cytokines [35], TNF-alpha signals through two transmembrane receptors, TNFR1 and TNFR2, and regulates a number of critical cell functions including cell immunity, inflammation, survival, differentiation, control of cell proliferation, and apoptosis [31,35,36,37]. TNFalpha is recognized by macrophages dramatically impacts the pattern of gene expression and hence investigating the mechanism of TNF-alpha signal transduction will be important in understanding how this molecule regulates macrophage differentiation [34]. TNF-alpha increases the proliferation of growth-competent macrophages in the presence of macrophage colony-stimulating factor-1 (M-CSF). TNF-alpha has also been shown to enhance the production of macrophages in vitro from primitive mouse hematopoietic progenitor cells [31,38]. The long-term survival of macrophages is dependent on autocrine signaling by TNF-alpha [18].

Tumor Necrosis Factor-alpha and IFN-gamma exhibit a cross-talk at the level of TNFR1 to induce activation of macrophages. TNF-alpha gene expression is regulated at the transcriptional level by several factors, including nuclear factor kappa $\mathrm{b}(\mathrm{NF} \kappa \mathrm{B})$ and nuclear factor activated $\mathrm{T}$ cells $(\mathrm{NF}-\mathrm{AT})(31,39,40]$. It has been shown that TNF-alpha induces a stronger activation of NFKB in the presence of IFN-gamma. Activated macrophages can migrate to sites of inflammation, where they encounter pathogens and lyses them. This is accomplished by an increased production of ROS and via induction of iNOS to produce NO [31].

Macrophages can produce large amounts of $\mathrm{NO}$ (nitrogen monoxide, *NO). The ability of *NO to react with $\left(\mathrm{O}_{2}{ }^{-}\right)$to produce peroxynitrite $\left(\mathrm{ONOO}^{-}\right)$was later recognized. As it is diffusion-limited, this reaction is more likely to occur in cells like macrophages that produce both ROS and RNS [41]. NO production is a key feature of immune cells. NO is principally synthesized by one of three NO synthase (NOS) enzymes: neuronal NOS (nNOS), inducible NOS (iNOS) and endothelial NOS (eNOS). The isoforms differ in respect to regulation, amplitude and duration of $\mathrm{NO}$ production, as well as cellular and tissue distribution [33,42].

Type 2 nitric oxide synthase (iNOS or NOS2) was originally described as an enzyme that is expressed in activated macrophages, generates NO from the amino acid L-arginine, and thereby contributes to the control of replication or killing of intracellular microbial pathogens. Since IFN-gamma is the key cytokine for the induction of NOS2 in macrophages and the prototypic product of type 1 T-helper cells, high-level expression of NOS2 has been regarded to be mostly restricted to the adaptive phase of the immune response [43]. At the interface between the innate and adaptive immune systems lies the high-output isoform of nitric oxide synthase (NOS2 or iNOS). Expression of NOS2 in macrophages is controlled by cytokines and microbial products, primarily by transcriptional induction. NOS2 has been documented in macrophages from human, horse, cow, goat, sheep, rat, mouse, and chicken [33].

Our study reveals that iNOS of macrophage (figure-1) increase on days 7 and on days 21 significantly ( $\mathrm{p}<$ 0.05) compare with before RF. This study shown that RF induce NO production by macrophage significantly. Macrophages, particularly when activated by interferon gamma or by lipopolysaccharide (LPS), have the capacity, 
through the production of $\mathrm{NO}$ and other intermediates, to destroy the remaining microorganisms in the inflammatory loci [25]. NO is a short-lived, diatomic, lipophilic gas that plays an integral role in defending against pathogens. Among its many functions are involvement in immune cell signaling and in the biochemical reactions [42], by which sustained production of NO endows macrophages with cytostatic or cytotoxic activity against viruses, bacteria, fungi, protozoa, helminths, and tumor cells [33,42]. The antimicrobial and cytotoxic actions of NO are enhanced by other macrophage products such as acid, glutathione, cysteine, hydrogen peroxide, or superoxide [33].

Nitrogen Oxide plays a pivotal role in the control of intracellular pathogens [30]. NO signaling directs a broad spectrum of processes, including the differentiation, proliferation, and apoptosis of immune cells. When secreted by activated immune cells, NO diffuses across cellular membranes and exacts nitrosative and oxidative damage on invading pathogens [42].

Macrophages are phagocytic cells that produce and release ROS in response to phagocytosis or stimulation with various agents [41]. Human macrophages appear capable of generating substantial amounts of superoxide anion $\left(\mathrm{O}_{2}{ }^{*^{-}}\right)$during phagocytosis which may play an important role in bactericidal and other cell functions [44], so macrophages play an essential role not only in the defense against the infection, but are involved in many various pathological processes [45].

Reactive Oxyge Species usually include superoxide anion $\left(\mathrm{O}_{2}{ }^{*}\right)$, hydrogen peroxide $\left(\mathrm{H}_{2} \mathrm{O}_{2}\right)$, and the highly reactive by-product of $\mathrm{H}_{2} \mathrm{O}_{2}$, hydroxyl radicals $(* \mathrm{OH})$ [35], whether produced endogenously as a consequence of normal cell functions or derived from external sources, pose a constant threat to cells living in an aerobic environment as they can result in severe damage to DNA, protein, and lipids $[35,46]$. The importance of oxidative damage to the pathogenesis of many diseases as well as to degenerative processes of aging has becoming increasingly apparent over the past few years [46]. The production of ROS by macrophages causes the pulmonary tissue damage, which seems to play a key role in this process [45]. ROS produced by TNF-alpha have an important function in cell death [47].

Our study reveal that SOD/ROS of macrophage on days 7 significantly decrease $(\mathrm{p}<0.05)$, but on days 21 decrease not significant compare with before RF. This study shown that RF reduces SOD/ROS production by macrophage or reduce oxidative stress on macrophage significantly in early period of RF. Analog with other study shown that fasting and caloric restriction have been associated with reduced incidence of chronic diseases and cancers. These effects have been attributed to reduced oxidative stress [48]. Contrary with study by Ibrahim et al. shown that RF does not alter oxidative stress parameters or biochemical markers of cellular damage in healthy subjects [49].

Superoxide is among the most abundant ROS produced by the mitochondria, and is involved in cellular signaling pathways [50]. Cells continuously produce free radicals and ROS as part of metabolic processes. These free radicals are neutralized by an elaborate antioxidant defense system consisting of enzymes such as superoxide dismutase [51]. Superoxide dismutase (SOD) enzymes catalyze the breakdown of superoxide into hydrogen peroxide and water and are therefore central regulators of ROS levels [50]. The enzyme responsible for the production of superoxide and hydrogen peroxide is a multi-component nicotinamide adenine dinucleotide phosphate-oxidase (NADPH oxidase) that requires assembly at the plasma membrane to function as an oxidase [41].

Generation of ROS is a normal process [52]. Free radicals and other ROS are constantly formed in the human body, often for useful metabolic purposes [53]. Under physiological conditions, these deleterious species are mostly removed by the cellular antioxidant systems, which include antioxidant vitamins, protein and non-protein thiols, and antioxidant enzymes [52]. Cells contain a number of antioxidant defenses to minimize fluctuations in ROS [46]. Exercise can produce an imbalance between ROS and antioxidants [51]. ROS generation often exceeds the cell's antioxidant capacity, resulting in a condition termed oxidative stress. [46]. An acute bout of exercise at sufficient intensity has been shown to stimulate activities of antioxidant enzymes. This could be considered as a defensive mechanism of the cell under oxidative stress [52]. Some of the pathways are preferentially linked to enhanced survival, while others are more frequently associated with cell death [46].

Oxidative stress can result from exposure to toxic agents, and by the process of tissue injury itself. Ozone, oxides of nitrogen, and cigarette smoke can cause oxidative damage; but the molecular targets that they damage may not be the same. Antioxidant defenses protect against them, but these defenses are not completely adequate, and systems that repair damage by ROS are also necessary. Mild oxidative stress often induces antioxidant defense enzymes, but severe stress can cause oxidative damage to lipids, proteins, and DNA within cells, leading to such events as DNA strand breakage and disruption of calcium ion metabolism [53].

Host survival depends upon the ability of cells and tissues to adapt to or resist the stress, and repair or remove damaged molecules or cells. Numerous stress response mechanisms have evolved for these purposes, and they are rapidly activated in response to oxidative insults [46]. An oxidative stress can depress macrophage function, 
but the dysfunction caused by a phagocytic challenge with immunoglobulin $\mathrm{G}$ (IgG)-coated erythrocytes EIgGs involves the $\mathrm{Fc}$ gamma receptor depletion and the erythrocyte contents rather than an oxidative stress [54].

Our study had shown that SOD/ROS of macrophage decrease during RF, significant on days 7 but not on days 21. This study suggests that RF can improve macrophage function cause by decrease oxidative stress on macrophage. Macrophages activated under conditions of oxidative or carbonyl stress can lead to a more enhanced inflammatory response. Coupled with an impairment of the phagocytic response, this can lead to ineffective clearance of apoptotic cells and secondary necrosis, with the result being failure to resolve the inflammatory response and the establishment of a chronic inflammatory state [22].

Development of intracellular killing activity by activated macrophages also requires the autocrine effects of TNF-alpha. IFN-gamma provides the first signal for the production of nitric oxide (NO), the effectors molecule for intracellular destruction of parasites. When IFN-gamma-treated cells are infected with pathogens, they are stimulated to make TNF-alpha [55].

Tumor Necrosis Factor-alpha alone did not directly induce macrophage NO2 production to kill amoebae; however, in combination with increasing concentrations of TNF-alpha and IFN-gamma, bone marrow-derived macrophages (BMM) amoebicidal activity and $\mathrm{NO}^{-}$production progressively increased and showed a significant linear correlation [56].

In our study had shown that iNOS production had significant strongly positive correlation with IFN-gamma before RF, but not on days 7 and on days 21 and had significant strongly positive correlation with TNF-alpha on days 7 , but not in before RF and days 21. Analog with regression test that iNOS more affected by TNF-alpha than IFN-gamma during RF. Other result had shown that SOD production had significant strongly negative correlation with IFN-gamma on before RF and on days 21 of RF, and had significant strongly positive correlation with TNFalpha on days 7, but become significant weakness negative correlation with TNF-alpha on days 21 of RF. Analog with regression test that SOD more affected by IFN-gamma than TNF-alpha during RF. This study suggests that RF altered the activated macrophage regulation / signaling in healthy subject.

Human NOS2 is most readily observed in monocytes or macrophages from patients with infectious or inflammatory diseases [33]. TNF-alpha is a powerful pro-inflammatory agent that regulates many facets of macrophage function. It is rapidly released after trauma, infection, or exposure to bacterial-derived LPS and has been shown to be one of the most abundant early mediators in inflamed tissue $[31,57,58]$.

Lipopolysaccharide (LPS)-activated macrophages secrete pro-inflammatory cytokines, including tumor necrosis factor (TNF) to elicit innate immune responses. Secretion of these cytokines is also a major contributing factor in chronic inflammatory disease [59]. Aberrant TNF-alpha production and TNF receptor signaling have been associated with the pathogenesis of several diseases [31]. TNF-alpha has been shown to play a pivotal role in orchestrating the cytokine cascade in many inflammatory diseases and because of this role as a "master-regulator" of inflammatory cytokine production, it has been proposed as a therapeutic target for a number of diseases [31,60]. Indeed anti-TNF-alpha drugs are now licensed for treating certain inflammatory diseases including rheumatoid arthritis and inflammatory bowel disease [31].

Our study reveal that TNF-alpha of macrophage increase significantly $(p<0.05)$ on days 7 but not significant on days 21 of RF. This study suggests that RF induce inflammatory on macrophage. Other study had shown that prolonged intermittent fasting in a model like RF has some positive effects on the inflammatory status of the body [61] and attenuates inflammatory status of the body by suppressing pro-inflammatory cytokine expression and decreasing body fat and circulating levels of leukocytes [62].

Inflammation is associated with production of cytokines and chemokines that recruit and activate inflammatory cells [63]. A large number of cytokines are found within foci of inflammation. Two of these cytokines, namely interleukin-1 (IL-1) and TNF. These two cytokines induce production by many cells of lipid mediators, proteases, and free radicals, all of which play a direct role in development of the deleterious effects of inflammation. IL-1 and/or TNF exert cytotoxic effects on the vascular endothelium, cartilage, bone, muscle, or pancreatic beta-cell islets. Cytokines, including interferon gamma (IFN), IL-3 and granulocyte-macrophage colonystimulating factor (GM-CSF), amplify the inflammatory response by increasing production of IL-1 and TNF by macrophages [60].

Macrophages also produce other cytokines, such as IL-8 and macrophage chemoattractant protein-1 (MCP-1), with chemoattractant properties that contribute to draw leucocytes to the site of inflammation. IL-6, produced in large amounts during inflammatory processes, induces the production of acute phase proteins by hepatocytes. IL-1, TNF, IL-11, leukemia inhibitory factor (LIF), and transforming growth factor beta (TGF beta) share this effect. TGF beta also has a number of anti-inflammatory effects. TGF beta, IL-4, and IL-10 inhibit production of IL-1 and TNF. Glucocorticoids also have this effect. Glucocorticoids can be produced as a result of a chain of events initiated by IL-1, TNF, and IL-6 and involving the neuro-endocrine axis. Other substances, such as 
IL-1 receptor antagonist (IL-1 ra) or soluble forms of the TNF receptors can specifically inhibit the effects of IL-1 and TNF [60].

Interleukin (IL) 12 produced by macrophages in response to various stimuli is a potent inducer of interferon (IFN) gamma production. IFN-gamma inhibition of chemokines production and inhibition of IFN-gamma-induced IL-12 production by TNF provide potential mechanisms by which these cytokines can exert antiinflammatory/repair function(s) [63]. Cascade production of cytokines, inhibition, negative feed-back, and synergistic mechanisms are parameters that illustrate the concept of "cytokine network" and aptly characterize the role of these mediators in the mechanisms of inflammation [60].

\section{CONCLUSION}

Our study suggests that RF induce classically activated, inflammation and decrease oxidative stress on macrophage. These studies also reveals that RF altered activated macrophage regulation / signaling and induces macrophage function and reveal that macrophage was in eustress condition, although are culture process contribute to stress response of macrophage still unknown.

\section{ACKNOWLEDGEMENT}

The authors would like to thank Bio-Medical Brawijaya University for technical assistance.

\section{REFERENCES}

[1]. Ardik Lahdimawan, Kusworini Handono, Rasjad Indra M., Sumarno Reto Prawiro. (2013). Effect of Ramadan Fasting on Endorphin and Endocannabinoid level in Serum, PBMC and Macrophage. International Journal of Pharmaceutical Science Invention (IJPSI), Vol. 2, issue 3; pp 46-54

[2]. Carrasco L., Villaverde C., Oltras C.M. (2007). Endorphin responses to stress induced by competitive swimming event.J Sports Med Phys Fitness; 47(2):239-45. [PubMed].

[3]. Choukèr A., Kaufmann I., Kreth S., Hauer D., Feuerecker M., Thieme D., Vogeser M., Thiel M. \& Schelling G. (2010). Motion sickness, stress and the endocannabinoid system. PLoS One; 5(5):e10752. [PubMed].

[4]. Caitlin J. Riebe \& Carsten T. Wotjak. (2011). Endocannabinoids and stress. Stress; 14(4): 384-397. [PubMed].

[5]. Chiurchiù V., Izzi V., D'Aquilio F., Vismara D., Carotenuto F., Catanzaro G., Maccarrone M. (2011). Endomorphin-1 prevents lipid accumulation via CD36 down-regulation and modulates cytokines release from human lipid-laden macrophages. Peptides; 32(1):80-5. [PubMed].

[6]. Lin J., Shen Y., Gao Y. \& Li L. (1997). Beta-Endorphin enhances IL-2 and IFN-gamma gene expression in human blood mononuclear cells. Zhongguo Yi Xue Ke Xue Yuan Xue Ba; 19(5):353-6. [PubMed].

[7]. Inui Y., Azuma Y., Ohura K. (2002). Differential alteration of functions of rat peritoneal macrophages responsive to endogenous opioid peptide endomorphin-1. Int Immunopharmacol; 2(8):1133-42. [PubMed].

[8]. Hosoi J., Ozawa H., Granstein R.D. (1999). Beta-Endorphin binding and regulation of cytokine expression in Langerhans cells. Annals of the New York Academy of Sciences 885: pg 405-13. [MedLine].

[9]. Pestonjamasp V.K., Burstein S.H. (1998). Anandamide synthesis is induced by arachidonate mobilizing agonists in cells of the immune system. Biochim Biophys Acta; 1394:249-260. [PubMed].

[10]. Bisogno T., Maurelli S., Melck D., De Petrocellis L., Di Marzo V. (1997). Biosynthesis, uptake, and degradation of anandamide and palmitoylethanolamide in leukocytes. J Biol Chem; 272:3315-3323. [PubMed].

[11]. Di Marzo V., De Petrocellis, Sepe N., Buono A. (1996). Biosynthesis of anandamide and related acylethanolamides in mouse J774 macrophages and N18 neuroblastoma cells. Biochem J; 316(Pt 3):977-984. [PMC]. [PubMed].

[12]. Rupal Pandey, Khalida Mousawy, Mitzi Nagarkatti, and Prakash Nagarkatti. (2009). Endocannabinoids and immune regulation. Pharmacol Res; 60(2): 85-92. [PMC].

[13]. Racz I., Nadal X., Alferink J., Baños J.E., Rehnelt J., Martín M., Pintado B., Gutierrez-Adan A., Sanguino E., Bellora N., Manzanares J., Zimmer A. \& Maldonado R. (2008). Interferon-gamma is a critical modulator of $\mathrm{CB}(2)$ cannabinoid receptor signaling during neuropathic pain. J Neurosci; 28(46):12136-45. [PubMed].

[14]. Blanchard D.K., Djeu J.Y., Klein T.W., Friedman H. and Stewart 2nd W.E. (1986). Interferon-gamma induction by lipopolysaccharide: dependence on interleukin 2 and macrophages. The Journal of Immunology, vol. 136 no. 3, $963-970$ [Abstract].

[15]. Han K.H., Lim S., Ryu J., Lee C.W., Kim Y., Kang J.H., Kang S.S., Ahn Y.K., Park C.S. \& Kim J.J. (2009). CB1 and CB2 cannabinoid receptors differentially regulate the production of reactive oxygen species by macrophages. Cardiovasc Res; 84(3):37886. [PubMed].

[16]. Wesemann D.R., Benveniste E.N. (2003). STAT-1 alpha and IFN-gamma as modulators of TNF-alpha signaling in macrophages: regulation and functional implications of the TNF receptor 1:STAT-1 alpha complex. J Immunol; 171(10):5313-9. [PubMed].

[17]. David M. Mosser. (2003). The many faces of macrophage activation. Society for Leukocyte Biology. Journal of Leukocyte Biology vol. 73 no. 2, 209-212 [Full Text].

[18]. Lombardo E., Alvarez-Barrientos A., Maroto B., Boscá L., Knaus UG. (2007) TLR4-mediated survival of macrophages is MyD88 dependent and requires TNF-alpha autocrine signalling. J Immunol; 178(6):3731-9. [PubMed].

[19]. Gattoni A., Parlato A., Vangieri B., Bresciani M., Derna R. (2006). Interferon-gamma: biologic functions and HCV therapy (type I/II) (1 of 2 parts). Clin Ter; 157(4):377-86. [PubMed].

[20]. Clark I.A. (2007). How TNF was recognized as a key mechanism of disease. Cytokine Growth Factor Rev;18(3-4):335-43. [PubMed].

[21]. Ahmed A.E., Aronson J., Jacob S. ((2000). Induction of oxidative stress and TNF-alpha secretion by dichloroacetonitrile, a water disinfectant by-product, as possible mediators of apoptosis or necrosis in a murine macrophage cell line (RAW). Toxicol In Vitro; 14(3):199-210. [PubMed]. 
[22]. Kirkham P. 2007Oxidative stress and macrophage function: a failure to resolve the inflammatory response. Biochem Soc Trans; 35(Pt 2):284-7. [PubMed].

[23]. Boyum A. (1968). Isolation of mononuclear cells and granulocytes from human blood. Isolation of monuclear cells by one centrifugation, and of granulocytes by combining centrifugation and sedimentation at $1 \mathrm{~g}$. Scand J Clin Lab Invest Suppl; 97:77-89. [PubMed].

[24]. Li-Min Ting, Anne C. Kim, Ashok Cattamanchi and Joel D. Ernst. (1999). Mycobacterium tuberculosis Inhibits IFN- $\gamma$ Transcriptional Responses Without Inhibiting Activation of STAT1. The Journal of Immunology, vol. 163, no. 7, 3898-3906. [Full Text].

[25]. Classen A., Lloberas J., Celada A. (2009). Macrophage activation: classical versus alternative. Methods Mol Biol; 531:29-43. [PubMed].

[26]. J. Christian J. Ray, Jian Wang, John Chan, and Denise E. Kirschnera. (2008). The timing of TNF and IFN- $\gamma$ signaling affects macrophage activation strategies during Mycobacterium tuberculosis infection. J Theor Biol; 252(1): 24-38. [PubMed].

[27]. Darwich L., Coma G., Peña R., Bellido R., Blanco E.J., Este J.A., Borras F.E., Clotet B., Ruiz L., Rosell A., Andreo F., Parkhouse R.M., Bofill M. (2009). Secretion of interferon-gamma by human macrophages demonstrated at the single-cell level after costimulation with interleukin (IL)-12 plus IL-18. Immunology; 126(3):386-93. [PubMed].

[28]. Boehm U., Klamp T., Groot M., Howard J.C. (1997). Cellular responses to interferon-gamma. Annu Rev Immunol; 15:749-95. [PubMed].

[29]. Ma J., Chen T., Mandelin J., Ceponis A., Miller N.E., Hukkanen M., Ma G.F., Konttinen Y.T. (2003). Regulation of macrophage activation. Cell Mol Life Sci; 60(11):2334-46. [PubMed].

[30]. Blanchette J., Jaramillo M., Olivier M. (2003). Signalling events involved in interferon-gamma-inducible macrophage nitric oxide generation. Immunology; 108(4):513-22. [PubMed].

[31]. Narayanan Parameswaran and Sonika Patial. ( 2010). Tumor Necrosis Factor-alpha Signaling in Macrophages. Crit Rev Eukaryot Gene Expr; 20(2): 87-103. [PMC].

[32]. Hibbs J.B., Jr. (2002). Infection and nitric oxide. J.Infect. Dis. 185(Suppl.1),S9-S17. [PubMed].

[33]. MacMicking J., Xie Q.W., Nathan C. (1997). Nitric oxide and macrophage function Annu. Rev. Immunol; 15,323-350. [PubMed].

[34]. Riches D.W., Chan E.D., Winston B.W. (1996). TNF-alpha-induced regulation and signalling in macrophages. Immunobiology; 195(4-5):477-90. [PubMed].

[35]. Shen H.M., Pervaiz S. (2006). TNF receptor superfamily-induced cell death: redox-dependent execution. FASEB J; 20(10):1589-98. [PubMed].

[36]. Witsell A.L., Schook L.B. (1992). Tumor necrosis factor alpha is an autocrine growth regulator during macrophage differentiation. Proc Natl Acad Sci USA; 89(10):4754-4758. [PMC free article] [PubMed].

[37]. Takada Y., Aggarwal B.B. (2004). Evidence that genetic deletion of the TNF receptor p60 or p80 in macrophages modulates RAN KLinduced signaling. Blood; 104(13):4113-4121. [PubMed].

[38]. Fahlman C., Jacobsen F.W., Veiby O.P., McNiece I.K., Blomhoff H.K., Jacobsen S.E. (1994). Tumor necrosis factor-alpha (TNFalpha) potently enhances in vitro macrophage production from primitive murine hematopoietic progenitor cells in combination with stem cell factor and interleukin-7: novel stimulatory role of p55 TNF receptors. Blood; 84(5):1528-1533. [PubMed].

[39]. Schütze S., Wiegmann K., Machleidt T., Krönke M. (1995). TNF-induced activation of NF-kappa B. Immunobiology; 193(2-4):193203. [PubMed].

[40]. Liu Q., Chen Y., Auger-Messier M. (2012). Interaction between NFאB and NFAT coordinates cardiac hypertrophy and pathological remodeling. Molkentin JD.Circ Res;110(8):1077-86. [PubMed]

[41]. Forman H.J., Torres M. (2001). Redox signaling in macrophages. Mol Aspects Med; 22(4-5):189-216. [PubMed].

[42]. David O. Schairer, Jason S. Chouake, Joshua D. Nosanchuk and Adam J. Friedman. (2012). The potential of nitric oxide releasing therapies as antimicrobial agents. Virulence; 3(3): 271-279. [PMC].

[43]. Bogdan C., Röllinghoff M., Diefenbach A. (2000). The role of nitric oxide in innate immunity. Immunol Rev; 173:17-26. [PubMed].

[44]. Weiss S.J., King G.W., LoBuglio A.F. (1978). Superoxide generation by human monocytes and macrophages. Am J Hematol; 4(1):18.[PubMed].

[45]. Zaloudiková M. (2012). NADPH-oxidase and the reactive oxygen species production by macrophages. Cesk Fysiol; 61(2):51-6. [PubMed].

[46]. Martindale J.L., Holbrook N.J. (2002). Cellular response to oxidative stress: signaling for suicide and survival. J Cell Physiol; 192(1):1-15. [PubMed].

[47]. Kim J.J., Lee S.B., Park J.K., Yoo Y.D. (2010). TNF-alpha-induced ROS production triggering apoptosis is directly linked to Romo1 and Bcl-X(L). Cell Death Differ; 17(9):1420-34. [PubMed].

[48]. Mo'ez Al-Islam Ezzat Faris, Rand Nidal Hussein, Ref'at Ahmad Al-Kurd, Mohammed Ahmed Al-Fararjeh, Yasser Khalil Bustanji, and Mohammad Khalil Mohammad. (2012). Impact of Ramadan Intermittent Fasting on Oxidative Stress Measured by Urinary 15-F $\mathrm{F}^{-}$ Isoprostane. J Nutr Metab; 802924. [PMC].

[49]. Ibrahim W.H., Habib H.M., Jarrar A.H., Al Baz S.A. (2008). Effect of Ramadan Fasting on Markers of Oxidative Stress and Serum Biochemical Markers of Cellular Damage in Healthy Subjects. Ann Nutr Metab; 53:175-181. [Abstract].

[50]. Landis G.N., Tower J. (2005). Superoxide dismutase evolution and life span regulation. Mech Ageing Dev; 126(3):365-79. [PubMed].

[51]. Urso M.L., Clarkson P.M. (2003). Oxidative stress, exercise, and antioxidant supplementation. Toxicology; 189(1-2):41-54. [PubMed].

[52]. Muaz Belviranl, Hakkı Gökbel. (2006). Acute exercise induced oxidative stress and antioxidant changes. European Journal of General Medicine, Vol.3, No.3, pp.126-131. [Full Text].

[53]. Halliwell B, Cross CE. (1994). Oxygen-derived species: their relation to human disease and environmental stress. Environ Health Perspect; 102 Suppl 10:5-12. [PubMed].

[54]. Raley MJ, Loegering DJ. 1999 Role of an oxidative stress in the macrophage dysfunction caused by erythrophagocytosis. Free Radic Biol Med; 27(11-12):1455-64. [PubMed].

[55]. Nacy C.A., Meierovics A.I., Belosevic M., Green S.J. (1991). Tumor necrosis factor-alpha: central regulatory cytokine in the induction of macrophage antimicrobial activities. Pathobiology; 59(3):182-4. [PubMed]. 
[56]. Lin J.Y., Seguin R., Keller K., and Chadee K. (1994). Tumor necrosis factor alpha augments nitric oxide-dependent macrophage cytotoxicity against Entamoeba histolytica by enhanced expression of the nitric oxide synthase gene. Infect Immun; 62(5): 1534-1541. [PMC].

[57]. Maini R.N., Elliott M.J., Brennan F.M., Feldmann M. (1995). Beneficial effects of tumour necrosis factor-alpha (TNF-alpha) blockade in rheumatoid arthritis (RA). Clin Exp Immunol; 101(2):207-12. [PubMed].

[58]. Feldmann M., Brennan F.M., Elliott M., Katsikis P., Maini R.N. (1994). TNF alpha as a therapeutic target in rheumatoid arthritis. Circ Shock; 43(4):179-184. [PubMed].

[59]. Micaroni M., Stanley A.C., Khromykh T., Venturato J., Wong C.X., Lim J.., Marsh B.J., Storrie B., Gleeson P.A., Stow J.L. (2013). Rab6a/a' Are Important Golgi Regulators of Pro-Inflammatory TNF Secretion in Macrophages. PLoS One; 8(2):e57034. [PubMed].

[60]. Cavaillon J.M. (1993). Contribution of cytokines to inflammatory mechanisms. Pathol Biol (Paris); 41(8 Pt 2):799-811. [PubMed].

[61]. Fehime B.A., Aynur E.T., Mahmut A. (2007). Interleukin-6, C-Reactive Protein and Biochemical Parameters during Prolonged Intermittent Fasting. Ann Nutr Metab; 51:88-95. [Abstract].

[62]. $\quad$ Faris M.A., Kacimi S., Al-Kurd R.A., Fararjeh M.A., Bustanji Y.K., Mohammad M.K., Salem M.L. (2012). Intermittent fasting during Ramadan attenuates proinflammatory cytokines and immune cells in healthy subjects. Nutr Res; 32(12):947-55. [Abstract].

[63]. Hodge-Dufour J., Marino M.W., Horton M.R., Jungbluth A., Burdick M.D., Strieter R.M., Noble P.W., Hunter C.A., Puré E. (1998). Inhibition of interferon gamma induced interleukin 12 production: a potential mechanism for the anti-inflammatory activities of tumor necrosis factor. Proc Natl Acad Sci USA; 95(23):13806-11. [PubMed]. 